\title{
The use of Pigeon pea (Cajanus cajan) for drought mitigation in Nigeria
}

\author{
M. E. Emefiene, A. B. Salaudeen, A. Y. Yaroson \\ Federal College of Forestry, P.M.B. 2019, Jos, Plateau State, Nigeria
}

\begin{abstract}
Drought poses one of the most important environmental constraints to plant survival and productivity and by implication-food insecurity in the tropics. Pigeon pea (Cajanus cajan) has the potential of fertilizing the soil thereby improving agricultural production and ensure green environmental and ecosystem stability. Despite the ability of the plant to improve soil fertility and promote greening environment, it has not attracted adequate awareness as a soil improvement plant. This paper highlights the information on the plant in order to intensify awareness for its widespread adoption to achieve the much desired sustainable resource use for greening our economy and environmental management. The successful widespread adoption of the plant will translate to effective drought, desertification and sustainable climate change mitigation approach in Nigeria.
\end{abstract}

Keywords: Drought; Pigeon pea; Environmental management; Mitigation and Desertification

\section{INTRODUCTION}

Desertification, as defined in Chapter 12 of "Agenda 21" and in the International Convention on Desertification, is the degradation of the land in arid, semi-arid and sub-humid dry areas caused by climatic changes and human activities. Princeton University Dictionary defines it as "the process of fertile land transforming into desert typically as a result of deforestation, drought or improper/inappropriate agriculture" (Google, 2012). It is accompanied by a reduction in the natural potential of the land and depletion in surface and ground-water resources. But above all it has negative repercussions on the living conditions and the economic development of the people affected by it. Desertification not only occurs in natural deserts, but can also take place on land which is prone to desertification processes. Desertification is a world-wide phenomenon which causes the earth's ecosystems to deteriorate. It affects about two-thirds of the countries of the world, and one-third of the earth's surface, on which one billion people live, namely, one-fifth of the world population.

The vulnerability of land to desertification is mainly due to the climate, the relief, the state of the soil and the natural vegetation, and the ways in which these two resources are used. Climate affects soil erosion and the chemical and biological deterioration of the soil. The state of the soil (texture, structure and chemical and biological properties) is a major factor, particularly in the sub-humid zones where the influence of climatic factors is less marked. It plays an essential role in causing vulnerability to desertification caused by human activities.

The same applies to the status of the natural and cultivated vegetation. Trees and bushes in particular, due to their long life and their capacity to develop powerful root systems, 
guarantee effective protection against soil degradation. Their disappearance considerably increases the vulnerability of the land to desertification. Lastly, even under the same conditions in terms of climate, relief, soils and vegetation, and with the same population density, the vulnerability of the land to desertification will vary widely depending on the way in which the natural resources are used by the human communities and their livestock.

Droughts occur frequently in the areas affected by desertification, and are generally a feature of their natural climate. The relations between desertification and drought on the one hand, and human influence on the other, are complex. Occasional droughts (due to seasonal or inter-year variations in rainfall) and long-term droughts covering wide areas are both caused or aggravated by the influence of man on the environment (the reduction in vegetation cover, the change in the Albedo effect, changes in the local climate, the greenhouse effect, etc.). Human influence can also hasten desertification and aggravate the negative consequences on man. But the degradation of land due to desertification has a serious compounding effect on drought, and thereby reduces the chances of the local people to cope with difficult periods.

Climatic changes are both a consequence and a cause of desertification. The destruction of the natural grass and woody vegetation cover in dry areas affects the topsoil temperature and the air humidity and consequently influences the movements of atmospheric masses and rainfall. Furthermore, the drying of the soils and the destruction of soil cover encourage air erosion.

Even though the cycles of drought years and climatic changes can contribute to the advance of desertification, it is mainly caused by changes in the ways man uses the natural resources, mainly by over-grazing, land clearance, over-cropping cultivated land and wood formations and more generally using land in a way that is inappropriate for the local conditions. Human activities connected with agriculture, livestock and forestry production vary widely from one country and from one type of society to another, as do the strategies for land-use and the technologies employed.

In many cases, traditional and durable rain fed agricultural methods (food crops and alternating fallow) and ancestral pastoral practices are no longer suitable under present-day conditions. Strong demographic pressure has increased the demand on land resources, and this is aggravated when cash-crop farming spreads to the detriment of subsistence farming and to the detriment of the rangelands used by nomadic peoples. However, the impact of human societies on natural resources does not depend solely on the demographic density, and the notions of "load capacity" and "critical threshold" must be handled with great care. Many examples demonstrate that these criteria can vary enormously, depending upon the strategies and the technologies used by the people.

The seriousness of desertification depends on factors which vary from one region, country or year to another. These factors include: the severity of the climatic conditions in the period considered (particularly in terms of the annual rainfall); population pressure and the standard of living of the people involved; the level of the country's development, and the quality of the preventive measures established there.

Pigeon pea remains one of the most drought tolerant crop (Valenzuela and Smith, 2002) and can give some grain yield during dry spells when other legumes such as field beans will have wilted and dried up (Okiror, 1986). Ability of pigeon pea to withstand severe drought better than many legumes is due to its deep roots (Flower and Landlow, 1987) and osmotic adjustment (OA) in the leaves (Subbarao, 2000). The legume maintains photosynthetic function during stress better compared to cow pea (Vigna unguicultala L. Walp) (Lopez et al, 1987). 
This paper advocates for inward focus and exploitation of adaptive qualities of pigeon pea for drought and desertification mitigation and creates awareness for its wide spread adoption so as to achieve the much desired sustainable resource use for green economy and environmental management.

\section{CAUSES AND FACTORS THAT LEAD TO DESERTIFICATION}

\section{1. Over-exploitation of natural resources}

Desertification is the accumulated result of ill-adapted land use and the effects of a harsh climate. Four human activities represent the most immediate causes: over-cultivation exhausts the soil, overgrazing removes the vegetation cover that protects it from erosion, deforestation destroys the trees that bind the soil to the land and poorly drained irrigation systems turn croplands salty. Moreover, the lack of education and knowledge, the movement of refugees in the case of war, the unfavorable trade conditions of developing countries and other socio-economic and political factors enhance the effects of desertification. The causes are multiple and interact in a complex manner.

Due to the lack of alternative survival strategies, farmers tend to relentlessly exploit natural resources (food crops, water for drinking and washing, firewood) to the point that they are often over-exploited and cannot regenerate naturally. Soil nutrients and organic matter begin to diminish as intensive agriculture removes quantities of nutrients greater than the soil's natural regeneration capacities. As a consequence, the soil is unable to recover, as it does during fallow periods, resulting is an ever-increasing spiral of environmental degradation and poverty, the principal causes of desertification.

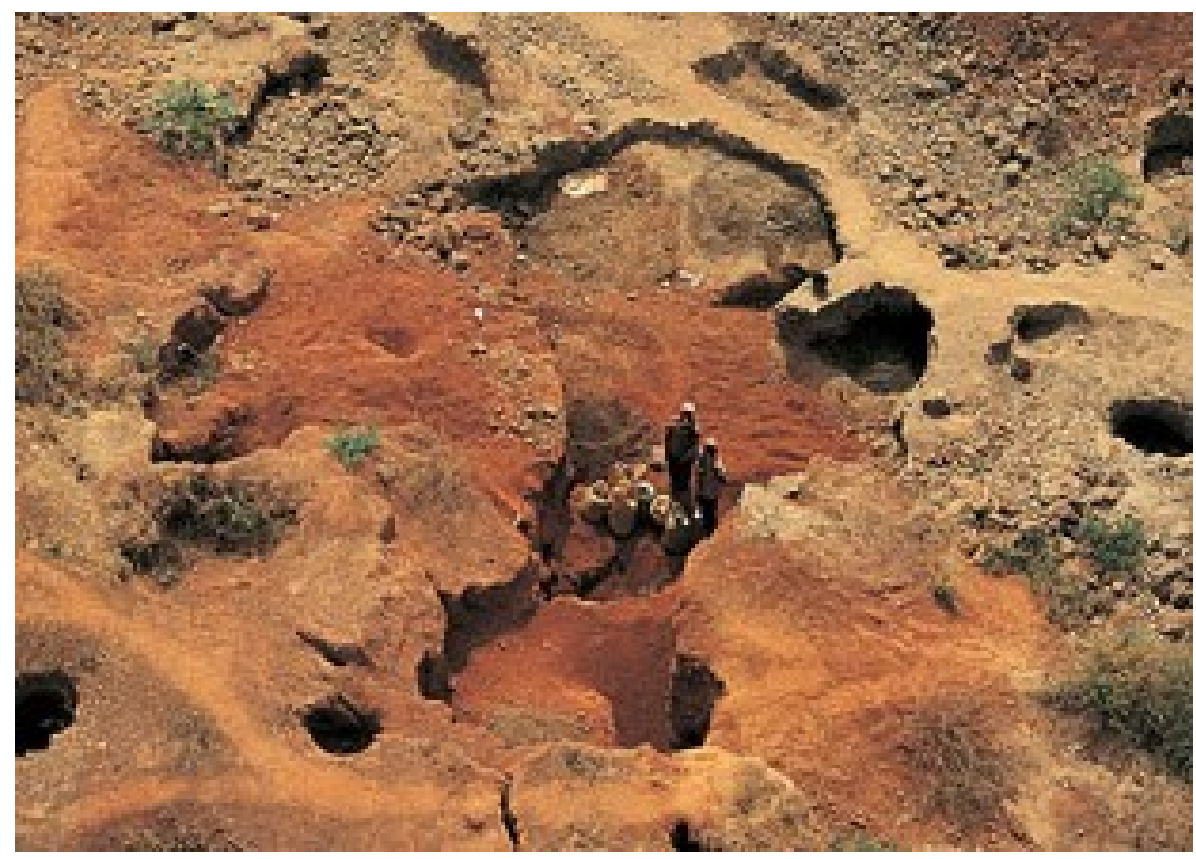

Source: Field Survey, 2013.

Katiola in the Côte d'Ivoire: diamond mines or precious metalopen or worse, monoculture; intensive labour; intense breeding and overgrazing with pressure on vegetation and soil trampling by livestock; separation of cattle rearing and agriculture, eliminating a 
source of quarries are a cause of desertification. Large surfaces are cleared and turned upside down hundreds of meters into the ground. When the mines are then disaffected the environment is totally destroyed rendering land rehabilitation almost impossible.

The principal causes exacerbating land degradation derives from the farmers' determination to maximize soil productivity, which include: crops cultivated in areas at high risk from drought; shortening of crop cycles and the reduction of fallow periods; insufficient use of fertilizer after harvesting; inadequate crop rotation natural fertilizer or organic matter (cattle dung) used to regenerate the soil; deforestation; bush and forest fires; in mountainous regions, crops are cultivated along the downward sloping face rather than following the natural contour lines of the mountain; deterioration of terraces and other soil and water conservation techniques.

\section{2. Deforestation and energy}

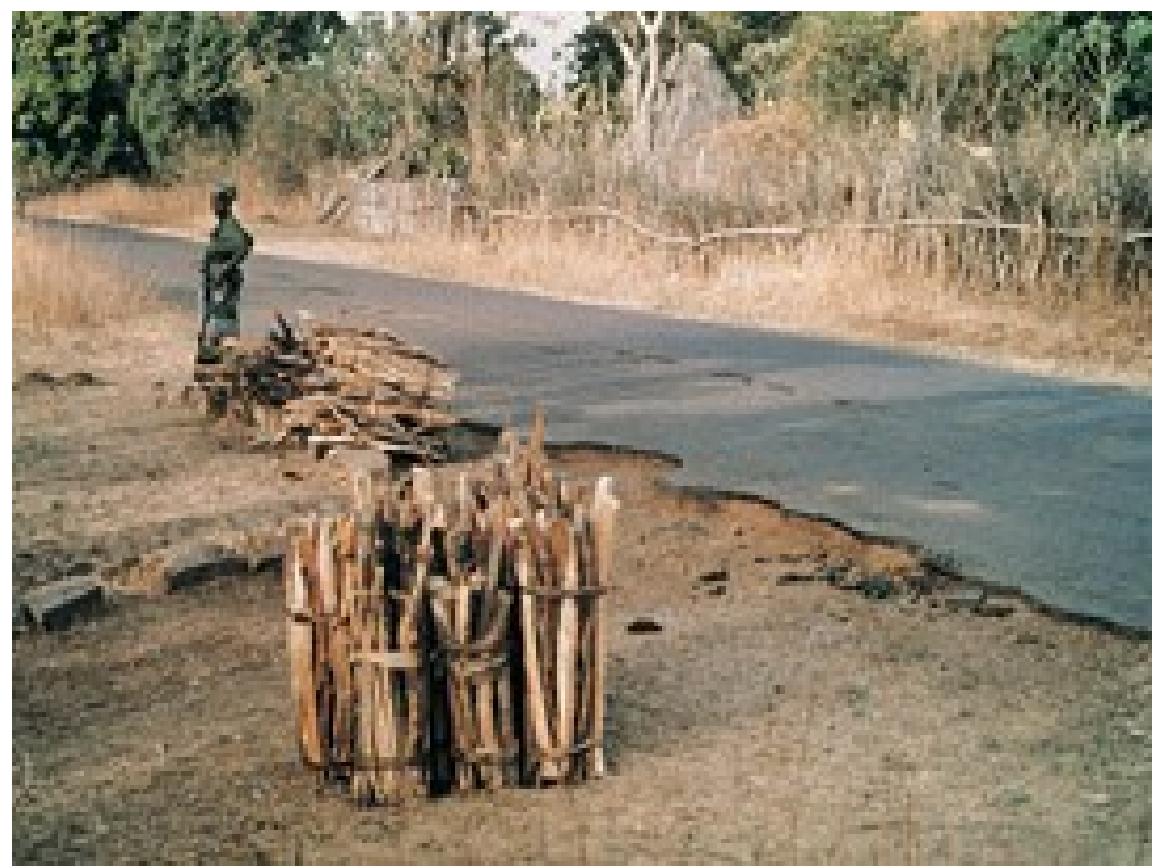

Source: Field Survey, 2013.

Deforestation is a major cause of desertification. In dry tropical zones, wood is the principal source of domestic energy and is also used in construction. In this way, large tracts of forest are destroyed. In the dry lands, forest regeneration is very slow because of water scarcity. The use of firewood is one of the principal causes of desertification. In tropical arid areas, wood is the principal source of domestic energy for cooking and lighting both in rural and urban populations. In order to limit the need for deforestation, only renewable sources of energy (hydraulic, wind, solar) and gas and petrol should be encouraged as it can replace wood consumption. Due to the lack of water in the dry lands, forest regeneration is very slow, reducing the dynamic growth of vegetation. However, allowing for rest periods from grazing and increasing fallow periods, generally have spectacular regenerating effects on the forest. 


\section{3. Population growth}

Since the middle of the 20th century many countries have experienced significant population growth (a greater number of children are born while infant mortality decreases slightly, but also people tend to live longer). As a result, the rate of population growth is often high: between $2 \%$ and $3 \%$ a year, meaning that in certain countries, the population will double within the next 20 to 30 years and with it, a growing population to feed.

The ensuing increase in agricultural pressure on land, with the added effect that the soil in the dry lands is not given sufficient time to recover, leads to an eventual drop in productivity. Paradoxally, human intervention is required to regenerate degraded lands. People have both the ability to destroy the land and the capacity to restore and rehabilitate their environment.

\section{4. Consequences at the local and national level}

By impoverishing the natural potential of the ecosystems, desertification also reduces agricultural yields, making them more unpredictable. It therefore affects the food security of the people living in the affected areas. The people develop a survival strategy in order to attend to their most urgent requirements, and this in turn helps to aggravate desertification and hold up development. The most immediate and frequent consequence of these survival attitudes is the increased over-exploitation of accessible natural resources.

This strategy is often accompanied by a breakdown in solidarity within the community and within households, and encourages individualism and exclusion. It leads to conflict between different ethnic groups, families and individuals. Lastly, desertification considerably heightens the effects of climatic crises (droughts) and political crises (wars), generally leading to migration, causing suffering and even death to hundreds of thousands of people worldwide.

These consequences, in turn, weaken the economies of the developing countries affected by desertification, particularly when they have no other resources than their agriculture. This is particularly true in the African countries in the dry zones: their economy is unable to offset the increasingly serious effects of desertification, and they have to deal with emergency situations created by drought and desertification despite the increasing debt burden that is reducing their possibility of making productive investment in order to break the spiral of underdevelopment.

While the survival attitudes caused by desertification have often led to a decline in agricultural know-how, they have conversely encouraged the development of technical knowhow, particularly relating to the environment and conservation. The micro-undertakings that have been implemented in many places over the past fifteen years have made it possible to build up a store of know-how to be able to implement new approaches. In many regions, the perception by the rural people of the importance of their environment and the priority given to a better relationship with the environment, have also changed.

More increasingly, rural people are realizing that: A fragile environment on which they depend for their survival is being neglected or over-exploited, and it is now necessary to rehabilitate it and manage it sustainably.

The environment belongs primarily to them, and that they must take the responsibility for the land and set up organizations (groups, cooperatives, village development associations and other local associations). Greater awareness at the highest level of government has also made it possible to draft and adopt the International Convention on Desertification, and the 
undertaking by the Heads of State of most of the world's countries to enter a partnership contract to effectively combat desertification by taking a participatory approach.

\section{5. Consequences at the global level}

Desertification also has consequences at the global level, primarily because of: The influence on carbon exchange. A substantial amount of carbon stored in the vegetation in the dry zones, averaging about 30 tonnes per hectare, declines when the vegetation is depleted or disappears.

Furthermore carbon-rich soils, which are frequently found in the dry zones, store an important amount of this element (practically half the total quantity of carbon is stored in the organic matter in soil, which is more than in the world's vegetation): the destruction of these soils has a very powerful effect on the carbon cycle and boosts the greenhouse effect as a result of the depletion of carbon; Another consequence of desertification at the local and global level is the reduction in biodiversity, since it contributes to the destruction of the habitats of animal and vegetable species and micro-organisms. It encourages the genetic erosion of local livestock and plant varieties and species living in fragile ecosystems.

It is extremely difficult to put a figure on this loss because of our inadequate familiarity with the features, the siting and the economic importance of the biodiversity of the dry zones. A substantial part of it is still fairly unknown to scientists, even though the local people are very familiar with it. Reducing the biodiversity directly affects the food and health of the local people who rely on a large number of different animal and vegetable species. But it is also a loss to the whole of mankind.

Many genetic strains of cultivated plants which form the basis of the food and health of the world's population originate from the dry zones: their disappearance can affect the possibility of producing plant-based medicines to combat specific diseases or epidemics; Lastly, desertification directly reduces the world's fresh water reserves. It has a direct impact on river flow rates and the level of groundwater tables.

The reduction of river flow rates and the lowering of groundwater levels leads to the silting up of estuaries, the encroachment of salt water into water tables, the pollution of water by suspended particles and salination, which in turn reduces the biodiversity of fresh and brackish water and fishing catches, interfering with the operation of reservoirs and irrigation channels, increasing coastal erosion and adversely affecting human and animal health. Lastly, desertification leads to an accelerated and often unbridled exploitation of underground fossil water reserves, and their gradual depletion.

\section{6. The extent of desertification}

The complexity of the causes of desertification and the diversity of its effects make it difficult to accurately evaluate its magnitude. Estimates of the areas affected or threatened by it are a matter of controversy because of the very complexity and diversity of desertification, and also the different notions of irreversibility in terms of the time scale considered. 
Source: Global Desertification Vulnerability Map.

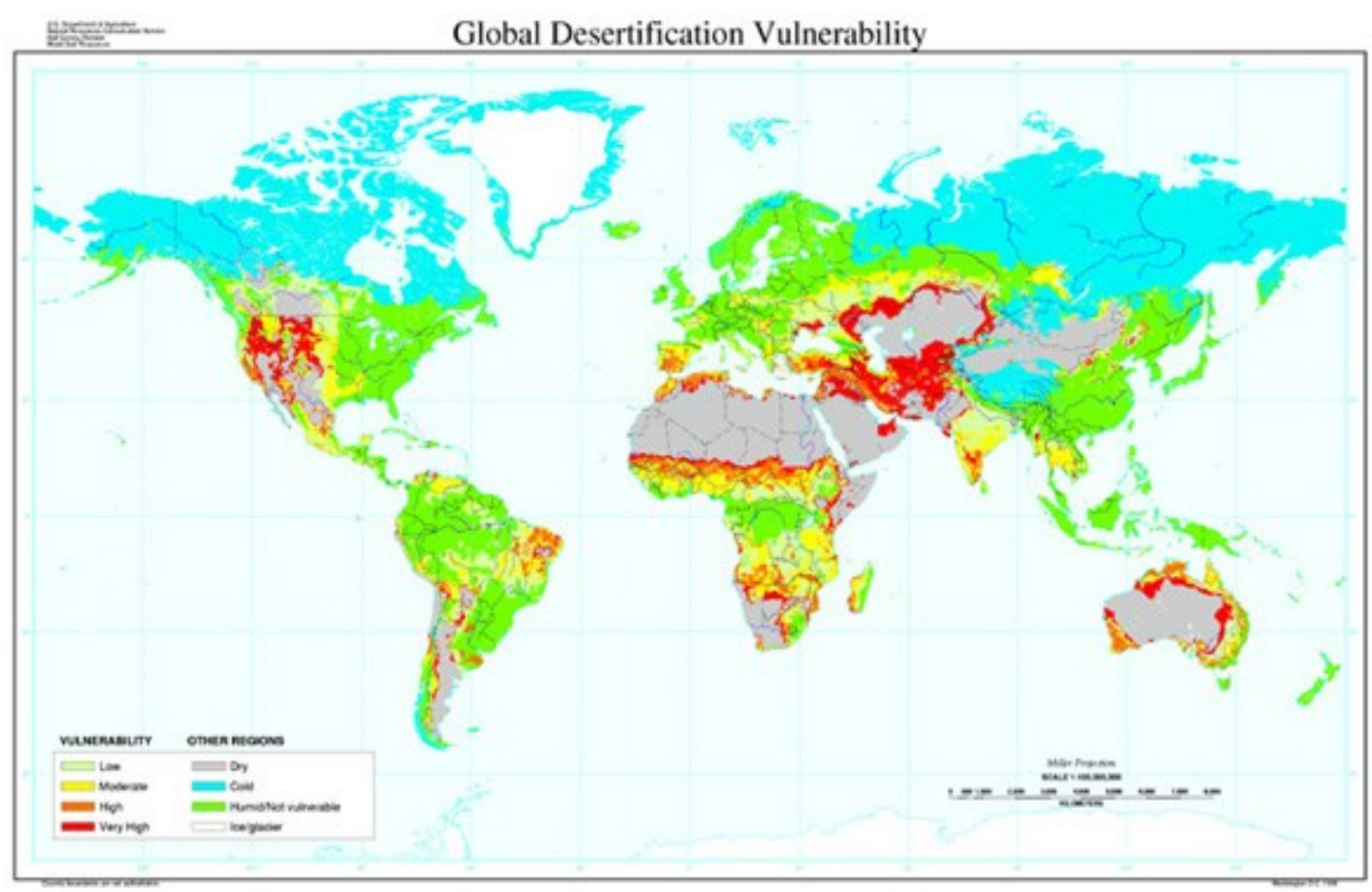

Source: Global Desertification Vulnerability Map.

\section{7. Pigeon pea}

Pigeon pea (Cajanus cajan) is an important drought tolerant grain legume. It is a multipurpose species, a diploid $(2 \mathrm{n}=22)$ belonging to the Cajaninae sub-tribe of the tribe phaseoleae, which also contains soybean (Glycine max L.), field bean (Phaseolus vulgaris L.) and mung bean (Vigna radiate L. Wikzek) (Young et al, 2003). It is the only known cultivated food crop of the 32 species that fall under the Cajaninae sub-tribe. The crop represents about $5 \%$ of world legume production (Hillocks et al,2000) with more than 70\% being produced in India (FAOSTAT,2007).

The crop is locally available in Nigeria, affordable and underutilized grain legume of the tropics and sub tropics. It has protein content in the range of 23-26\% (Oshodi et al, 1985). The protein content is comparable with those in other legumes like cowpea and groundnut which has been used in complementing maize diet. It is rich in mineral quality and fiber content. It grows well in Nigeria (Enugu, Benue) but the hard- to- cook phenomenon and the presence of anti-nutrients have limited its utilization (Nene et al, 1984; Eltabey,1992). There is also substantial pigeon pea production in Eastern Africa and the Americas. Global annual production of pigeonpea is about 3.6 million tones $(\mathrm{Mt})$ valued at around U.S. \$ 1600 million (FAOSTAT, 2007).

The use of drought tolerant legumes will be important in Africa where rapid expansion of water-stressed areas has been projected (Postel, 2000). There is great potential for expansion of the crop in regions of Africa where it would also counteract the declining soil fertility (Hillocks et al, 


\section{QUALITIES OF PIGEONPEA FOR DROUGHT MITIGATION ALLEVIATION}

A. Drought Tolerant: Pigeonpea remains one of the most drought tolerant legumes and is the only crop that gives some grain-yield during dry spells when other legumes such as field bean will have wilted and dried up. The ability to withstand severe drought is attributed to its deep roots and osmotic adjustment in the leaves.

B. Photosynthetic Functions During Stress: It maintains photosynthetic functions during stress compared to other drought tolerant legumes such a cowpea (Vigna uguiculata).

C. Nutrient Cycling: It recycles nutrient.

D. Moisture Storage: Its initial slow growth reduces competition for light, water, and soil nutrients.

E. It has the ability the ability to fix up to $235 \mathrm{~kg}$ Nitrogen $(\mathrm{N}) / \mathrm{ha}$ and produce more $\mathrm{N}$ per unit from plant biomass compared to other legumes.

\section{BENEFITS OF PIGEON PEA}

Nutrient recycling; Moisture storage; Highly nutritious for consumption; Good source of amino acids; Green manure crop; Fodder and forage crop; Medicinal; Food supplement and Weed control.

\section{DROUGHT, VULNERABILITY, ADAPTATION AND MITIGATION}

Drought is natural part of climate that affects nearly every region on earth (Wilhite, 2000; Wilhite and Buchanan, 2005). Although specific definitions of drought may vary by sector and region, drought generally originates from a deficiency of precipitation over an extended period of time, resulting in a water shortage for some activity, group, or environmental sector.

Vulnerability refers to the potential to be adversely affected by an event or change. The extent to which drought may damage or harm a system depends on the level of exposure, the systems sensitivity and ability to adapt to new conditions. Vulnerability therefore, is a function of exposure, sensitivity and adaptive capacity which may be considered at many levels including individual, household and nationally (Orinde et al, 2006). According to the Nigerian Maritime Administration and Safety Agency (NIMASA, 1999) poor people are mostly vulnerable to deviations from the average climatic conditions such as prolonged drought and national disasters such as floods. Currently, Nigeria is experiencing adverse climatic conditions with negative impacts on the welfare of millions of peoples as a result of persistent droughts and flooding. Off season rains and dry spell have sent growing up and rivers flow in the arid and Sub-Saharan regions reducing, which results in fewer water supplies for agriculture, hydroelectric power generation and other uses.

Mitigation means actions that we can take before or at the beginning of drought to help reduce the impacts of drought. Mitigating drought involves a wide range of agricultural practices including finding additional water supplies and conserving water that is already available. However, it is not enough to make drought plans based only on agricultural practices. There are many other strategies at government level that are just as important. It is important to realize that we will not be able to defend drought overnight. Some of these 
strategies will take time to implement an d to see the result. We continually need to plan and to follow the plans in order to prevent drought from having devastating impact on life.

\section{STRATEGIES FOR MITIGATING DROUGHT}

\section{1. The Crop based strategies for mitigating drought are}

Land planning system; Soil management techniques; Crop management techniques; Integrated watershed management; Other water management technique; Other practices

\section{2. Land planning systems}

Some lands can only sustain limited cultivation because they are prone to drought. These are best used for alternate uses rather than normal food grain crops. Land-use systems give stability to dry land production systems and also make good use of the land and rainfall during the off-season.

\section{3. Some examples of alternate crops you can grow are}

Growing of short duration legume crops; Establishing perennial grasses for livestock farming; Agroforestry or silvipasture practices.

\section{4. Soil management techniques:}

Tillage during the off-season or in pre-rainy season, helps with rain water intake by breaking the hard soil and making the soil surface more permeable; This allows water to seep to the deeper soil layers and keeps the soil wet for longer time; The result is the soil will have more moisture during sowing the crop; Tillage also controls weeds which depletes the soil moisture; Off-season tillage also destroys the effs, cocoons and larvae of some pests by exposing them to the sun which otherwise affect the already stressed crop plants.

\section{5. Crop management techniques}

Selection of Crops: Avoid growing of drought prone crops like maize, cotton etc; Growing drought resistant grain crops like sorghum, pearl millet, finger millet, fox tail millet etc. Growing drought resistant legume crops like pigeonpea, green gram, horse gram etc; Growing of oil seed crops like castor, sunflower, niger, sesame, safflower etc.

Intercropping practices: Intercropping refers to growing more than one crop in the same land area in rows of definite proportion and pattern. Intercropping system provides insurance against total crop failure in drought prone areas. A few examples of suitable intercropping systems under drought are: Sorghum and Pigeonpea; Pearl millet and Pigeonpea; Pearl millet and Cowpea; Sunflower and Horse gram

Plant Density: It is important to keep optimum plant population and row spacing. Generally wider plant spacing is preferred in drought prone areas. There is need for carefulness not to space the plants too widely. This will not use available soil moisture to the capacity.

Weed management: Weeds compete with crops for soil moisture and nutrients; Weeds also hosts some pests and diseases and these will migrate and affect the crops which are already under stress under drought conditions; So, good weed control from the early stages of crops is essential in drought areas. 
Surface Mulching: Surface mulching either by timely inter cultivation or by covering the soil surface with plant residues benefits the crops; Reduce water evaporation from soil; Reduces water runoffs from the cropped fields; Help control weeds; Adds organic matter to the soil and improves soil quality.

Integrated Nutrient Management (INM): INM takes care of physical, chemical and biological needs of the soil. It meets the nutrient needs of the soil from the use of organic and inorganic fertilizers.

Benefits of INM: Increases water holding capacity of the soil; Increases the amount of nutrients in the soil; Make the soil more resistant to diseases; Make the soil better able to withstand drought.

Integrated Water Management (IWM): IWM is the efficient way to continually manage land and water resources in the drought prone areas. The focus of IWM is conservation and efficient way of using rain water. IWM combines several approaches to minimize the risk of drought.

These approaches are: Soil and water conservation; Rain water harvesting; Efficient land and crop management

Other Water management techniques: Every drop of water will make a difference during drought and so efficient conservation of rain water is key to mitigate drought. The different methods of conserving water are: Building masonry storage tanks and broken embankments in community ponds and reservoirs; Building earth percolation ponds and reservoirs; Desilting all water storage structures; Building check dams; Rooftop rain water harvesting.

\section{CONSTRAINTS}

Despite the modernization of observation facilities by the use of satellite imagery and computers to analyze the data, there are still many uncertainties at the global, regional and national level on the causes, the extent and the seriousness of desertification. For those who manage natural resources, these uncertainties prevent them from planning properly. They also introduce constraints on the operation of early warning systems with regard to agricultural production and disasters such as grasshopper infestations.

\section{ECOMMENDATION}

Above all, at the national and local level information is urgently necessary. The results of high spatial and spectrum resolution satellite images such as SPOT or Landsat images, combined with high-frequency low resolution satellite data such as Meteosat and NOAA data, can be used by the geographic information systems and completed by the results obtained from the new methods of collecting soil data using navigation satellites (GPS).

These methods, whose development supported by FAO, would make it possible to observe, evaluate and monitor both the bio-physical and the socio-economic aspects of desertification. Drought must be addressed in an integrated fashion with the other themes of the current Commission on Sustainable Development cycle, considering social, economic and environmental aspects. Strategies for drought management, including contingency planning should be incorporated into sustainable agricultural practices, soil conservation, crop 
diversification and integrated water resources management and combating desertification, taking into account the legal framework and mandate of the United Nations Convention to Combat Desertification and its role in mitigating the effects of drought.

\section{CONCLUSION}

This paper thus advocates pigeon-pea as an important crop with great potential for success in Nigeria. Increased production of Pigeon pea can do much towards greening our economy and environment and address food crisis in Nigeria. The great potentials in marketing organic Pigeon pea will go a long way to boost international markets. Local consumption of pigeon pea by Nigerians must be encouraged by introducing its use in various forms and creating awareness of its nutritional, green economy, drought mitigation and environmental management benefits.

\section{References}

[1] Agona J. A., Muyinza H. (2005). Promotion improved handling, processing, utilization and marketing of pigeonpea in Apec district. Technical Report. United Kingdom. Department for International Development (DFID)-The National Agricultural Research Development (NARD). Client Oriented Research Fund (CORF) (2006) Project.

[2] Atachi P., Machi B., Annales des Scinces Agronomiques du Benin 6(2) (2004) 1-2.

[3] ICRSAT (2013). http://vasat.icrisat.org/How can we mitigate drought_a virtual coalition to mitigate drought preparedness.htm.

[4] Whilhite D. A., Drought as a natural hazard: Concepts and definitions. In: Drought: A Global Assessment, Vol.1, Whilhte, D.A. (ed). Routledge, New York, 2000, pp. 1-18.

[5] Whilhite D. A., Buchanan, M. (2005). Drought s hazard: Understanding the natural and social context. In: Drought and Water Crisis: Science, Technology and Management Issues, Whilhite, D.A. (ed.). CRC. Press (Taylor amd Francis), New York, pp. 3-29.

[6] Lynn M. Wagner, Yearbook of International Environmental Law 21(1) (2011) 310-312. doi: 10.1093/yiel/yvs014. 